\section{Gene-drive e-mails legally requested}

Gene-drive technology does indeed need proper scrutiny, but it also needs transparent and accountable governance (see Nature 552, 6; 2017). In my view, your Editorial seems to be trying to excuse the influence of big-money manipulations on scientific decision-making when it comes to this risky technology. In so doing, I feel that Nature has crossed a line in conflating a cornerstone of investigative journalism - requests under freedom-of-information laws with outright theft.

Specifically, you write that the release of 1,200 e-mails from gene-drive researchers (obtained by Edward Hammond under US open-records laws) "echoes the way in which hackers released documents stolen from climate scientists before a major UN meeting in 2009". The two incidents are very different. Those 'Climategate' e-mails were taken illegally. These e-mails, dubbed the Gene Drive Files, were released by the institutions involved in accordance with legal requirements. There is nothing criminal about this.

Furthermore, climate deniers used the Climategate e-mails to claim that data had been falsified. Scientists robustly and correctly responded through independent inquiries that this was incorrect. By contrast, the Gene Drive Files concern issues of process: they corroborate how the Bill \& Melinda Gates Foundation in Seattle, Washington, paid US\$1.6 million to a private public-relations firm, apparently with the intention of influencing the United Nations discussion on gene drives by coordinating what an 'advocacy coalition' of public researchers should say in an expert process. Nature failed to provide the details but readers can make up their own minds.

Employment as a researcher at a publicly funded institution is an immense privilege. Such researchers are rightly accountable to the public not to private public-relations firms or big-money agendas. Accountability is exactly why we have freedom-of-information laws. Undermining those laws undermines a free press.

Jim Thomas ETC Group,

Montreal, Canada.

jim@etcgroup.org

J.T. declares competing financial interests; see go.nature.com/2ctjftu

\section{Arm against return of breast cancer}

Your summary of the latest study by the Early Breast Cancer Trialists' Collaborative Group, states that "Even after treatment, odds of recurrence are worse for the next 20 years" (Nature http://go.nature.com/2eob74j; 2017). We find this statement unnecessarily alarming.

The same group showed in previous work that, at 15 years of follow-up, women with oestrogen-receptor-positive breast cancer who received adjuvant endocrine therapy (AET) with the drug tamoxifen for 5 years had a reduced risk of recurrence (risk reduction, 47\%) and of related mortality (risk reduction, 29\%). The yearly rate of death related to breast cancer also dropped by about one-third throughout the first 15 years (see Early Breast Cancer Trialists' Collaborative Group Lancet 378, 771-784; 2011). Women with this cancer type who did not receive this treatment had a $46.2 \%$ probability of recurrence of breast cancer at 15 years.

The ATLAS randomized trial showed that extending AET with tamoxifen treatment from 5 to 10 years reduced the risk of relapse (risk reduction, 30\%) and of related mortality (risk reduction, $48 \%$ ) after completion of therapy. The benefits of the treatment were reaffirmed by the aTTom randomized trial (G. Schiavon and I. E. Smith Breast Cancer Res. 16, 206; 2014). These findings changed clinical practice. The American Society of Clinical Oncology guidelines now recommend that women with oestrogen-receptor-positive breast cancer should consider 10 years of AET with tamoxifen. Balkees Abderrahman, V. Craig Jordan University of Texas MD Anderson Cancer Center, Houston, Texas, USA. bhabderrahman@mdanderson.org

\section{Fragile ecosystems to test climate targets}

At the 2015 climate summit in Paris, negotiators adopted $2^{\circ} \mathrm{C}$ as the upper limit for global warming, with a view to limiting it to $1.5^{\circ} \mathrm{C}$. I suggest that more research is needed into ecosystems that are highly sensitive to temperature shifts and that deliver multiple ecosystem services, such as mountains and corals. Such work could help in the assessment of these targets and of the risks associated with climate-mitigation options such as bioenergy and geoengineering.

The Intergovernmental Panel on Climate Change is moving forward with its special report on the $1.5^{\circ} \mathrm{C}$ warming and its Sixth Assessment Report. Each document will need to consider the future impacts of the two targets on biodiversity, ecosystems and humans - and what it would take to achieve the $1.5^{\circ} \mathrm{C}$ target.

In the Himalayas, for example, projected mean increases of $1.8^{\circ} \mathrm{C}, 2.2^{\circ} \mathrm{C}$ and $3.7^{\circ} \mathrm{C}$ in global mean surface temperatures for 2081-2100 (relative to 1986-2005) would lead to significantly greater loss of glaciers than if the projected increase is $1.5^{\circ} \mathrm{C}$ or less (P. D. A. Kraaijenbrink et al. Nature 549, 257-260; 2017). These glacier changes would affect biodiversity and human populations by altering species distributions, water regimes, farming and the risks of outburst floods from glacier lakes. Ignacio Palomo Basque Centre for Climate Change, Leioa, Spain. ignacio.palomo@bc3research.org

\section{A serious nonsense publishing proposal}

The surge in open-access predatory journals is making it harder for contributors and readers to distinguish these from legitimate publications - a confusion that is fostered by the predatory-journal industry. One solution could be to deploy a variant of a well-established quality-control test.

The scientific community could submit replicate test articles several times a year to a wide array of open-access journals, suspect and non-suspect. These manuscripts would use the organization and language of legitimate science but would be readily identifiable as nonsense to someone in the field. The process should be undertaken by an independent group, perhaps under the auspices and oversight of the Directory of Open Access Journals or the US National Library of Medicine.

The results could then be made public to form the basis of a 'journal integrity index'. This would avoid labelling journals as predatory and reduce the risk of legal retribution.

Such an objective assessment of legitimate editorial practice, which is currently almost impossible to verify, could help to eliminate the scourge of fake journals that is threatening the scientific enterprise.

Steven N. Goodman Stanford University, California, USA. steve.goodman@stanford.edu

\section{CORRECTION}

The Outlook article

'Combinations on trial'

(Nature 552, S67-S69; 2017)

overstated the number of immunotherapeutic agents in development at more

than 2,400 . In fact, there are roughly 2,000 . 